\title{
Minas melancólica: poesia, nação, modernidade
}

\author{
Reinaldo Marques \\ Universidade Federal de Minas Gerais
}

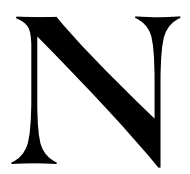

o ensaio "Tempos modernos, poetas melancólicos", 1 observei a recorrência do tema da melancolia, com suas variantes, na poesia de um expressivo grupo de poetas mineiros atuante nas décadas de 30, 40 e 50: Carlos Drummond de Andrade, Abgar Renault, Henriqueta Lisboa, Octávio Dias Leite. Mas não só na poesia, posto que também na correspondência recíproca entre Drummond e Abgar Renault, há referências reiteradas à melancolia, à tristeza. Em carta de 15-01-1949, diz Abgar:

A vida é realmente uma cousa triste, fundamentalmente triste. À proporção que andamos, os caminhos vão ficando mais escuros e mais amargos, e, antes de chegarmos ao fim, perdemos tanta cousa de nós mesmos, de tanto e tanto somos despojados, que não somos nunca senão uns restos pobres e lamentáveis de nós próprios. (... $)^{2}$

Já em carta de 04-12-1953, confessa ao amigo Drummond o seu fraco pelo poema "Estrambote melancólico", cujo título o seduz fortemente. De sua parte, o poeta de Itabira assinala, em carta de 12-12-1952:

Meu caro Abgar, só mesmo a sua "Canção oculta" podia arrancar-me do torpor em que mergulhei nesses últimos dias e que vai se tornando para mim, pela reincidência, uma espécie de atmosfera moral. Você me mandou um auxílio, não um poema. Costumo pedir à poesia umas razões provisórias de vida, para espantar a chatice do meu dia, mas encontro cada vez menos poesia a que me abrigue.

\footnotetext{
${ }^{1}$ Publicado em SOUZA, (Org.), 1998. p. 157-172.

${ }^{2}$ As cartas de Abgar Renault e Carlos Drummond de Andrade, aqui citadas, encontram-se no Arquivo-Museu de Literatura Brasileira da Fundação Casa de Rui Barbosa.
} 
Frente a esse torpor que lembra a acedia do melancólico, as cartas do amigo parecem um consolo, que vale muito no "dia melancólico", conforme carta de 14-11-1953.

Disseminando pela obra desses poetas atmosfera ora difusa ora compacta, tal reiteração nos permite tomar a figura do melancólico como uma metáfora esclarecedora das relações do poeta com o mundo moderno e com o lugar problemático que lhe cabe no espaço da modernidade. Particularmente quando se trata de uma modernidade tardia, que parece se realizar de forma truncada e inacabada em espaços periféricos, como reflexo de um projeto de modernidade centrado, traçado nas metrópoles colonizadoras.

Essa atmosfera melancólica, marcada tanto por imagens da morte e de um passado em ruínas, quanto por um vívido sentimento de tristeza, de ensimesmamento do eu, de angústia existencial frente ao fluir inexorável do tempo, parece não se constituir, no entanto, em privilégio da poesia e de poetas. Ela contamina também prosadores, romancistas e memorialistas mineiros, como demonstram as obras de um Autran Dourado ou de um Lúcio Cardoso, a exemplo de Ópera dos mortos e Crônica da casa assassinada. ${ }^{3}$ Tal observação assinala a existência de uma Minas Gerais melancólica, ruminando ensimesmada seu passado e interrogando angustiada seu futuro. Trata-se aqui, obviamente, de uma Minas literária e de uma melancolia escrita, bem diversa da realidade depressivo-melancólica dos manicômios com seus pacientes. Mas essa Minas melancólica constituise num contraponto interessante a uma Minas salvacionista cunhada pela política, por certa visão mítica da mineiridade, elevada à condição de ponto de equilíbrio no jogo de forças em disputa pelo poder.

Segundo Walter Benjamin, "o herói é o verdadeiro objeto da modernidade. Isso significa que, para viver a modernidade, é preciso uma constituição heróica", ${ }^{4}$ dado que ela oferece enormes resistências ao natural impulso produtivo do homem, desproporcionais às suas forças. Se a experiência da modernidade requer uma "constituição heróica", podese afirmar, entretanto, que o herói da modernidade é um herói melancólico. No caso dos poetas mineiros dos quais nos ocupamos aqui, caberia examinar em que consiste sua constituição heróica melancólica, explicitando suas motivações e implicações, o que procurarei fazer agora de forma suscinta

\footnotetext{
${ }^{3}$ Sobre a melancolia nesses romancistas, Cf. LOPES, 1999.

${ }^{4}$ BENJAMIN, 1989. p. 73.
} 
e pontual, articulando as noções de poesia, nação e modernidade e relacionando a questão da melancolia ao papel e aos desafios do poeta, do intelectual, no âmbito da modernidade.

Minha hipótese, e ponto de partida, é a de que essa Minas literária e seus poetas afeitos à melancolia afirmam um saber melancólico, calcado no fragmentário e no descontínuo, capaz de produzir um distanciamento crítico em relação a uma racionalidade moderna abstrata e totalizante, instrumental e técnica, atuante num espaço periférico. Racionalidade esta que configura e fundamenta o projeto de reconstrução e modernização do Brasil levado a cabo pelo Estado Nacional do pós-30. A esse projeto haverá de se integrar, conforme demonstra Helena Bomeny, aquela primeira geração modernista mineira, dos intelectuais da Rua da Bahia, desempenhando um papel fundamental na definição de políticas educacionais e culturais do governo Vargas, conferindo a um projeto cultural regional uma dimensão nacional. ${ }^{5}$ Dentre esses intelectuais cabe destacar os nomes de Francisco Campos, Gustavo Capanema, Rodrigo Melo Franco de Andrade, Carlos Drummond de Andrade e Abgar Renault.

A hipótese aventada acima atribui à melancolia uma produtividade positiva, desvinculando-a da perspectiva patológica que lhe emprestou Freud. Em parte, isso se explica por se tratar daquela melancolia escrita, perlaborada pelo trabalho artístico-literário. Para Julia Kristeva, como aventura do corpo e dos signos, a criação literária dá testemunho do afeto, transpondo-o em ritmos, signos e formas. O que asseguraria um domínio ainda que incerto, mas adequado, sobre a Coisa, de tal sorte que o semiótico e o simbólico constituem marcas comunicáveis de uma realidade afetiva presente, entretanto dominada e afastada, que toca o leitor. ${ }^{6}$ Em parte também devido à ambigüidade própria da melancolia que, se de um lado contém uma dimensão paralisante e destrutiva, de outro, apresenta um comportamento altamente reflexivo, dotando o melancólico de talentos intelectuais notáveis, em que sobressaem a qualidade dos raciocínios. Daí que para os Antigos, conforme assinala Marie-Claude Lambotte, a melancolia venha a se constituir numa excitação furiosa do pensamento, isto é, da capacidade de raciocinar, semelhante à embriaguez do vinho. ${ }^{7}$

${ }^{5}$ Cf. BOMENY, 1994.

${ }^{6}$ Cf. KRISTEVA, 1989. p. 28-29.

7 LAMBOTTE, 2000. p. 33. 
Em "Luto e melancolia", Freud estabelece estreitas relações entre o luto e a melancolia. Ambos constituem uma reação à perda de um ente ou objeto querido, comportando um estado de espírito penoso, o desinteresse pelo mundo, a inibição do eu. Todavia, segundo Freud, no trabalho do luto prevalece o princípio da realidade e, depois de certo lapso de tempo, o eu se mostra capaz de substituir o objeto perdido por outro, retomando suas relações com o mundo externo. Já o mesmo não se dá com a melancolia, uma vez que a elaboração da perda não se completa. E não se completa, supõe Freud, porque o sujeito melancólico não sabe exatamente o que se perdeu. O que sugere que "a melancolia está de alguma forma relacionada a uma perda objetal retirada da consciência, em contraposição ao luto, no qual nada existe de inconsciente a respeito da perda". ${ }^{8}$ Daí que, diversamente do trabalho do luto, a inibição do melancólico apresente um caráter enigmático, dado que não se sabe o que o absorve tão completamente. Mais ainda, no melancólico há um empobrecimento do eu, visível na insatisfação com o ego, objeto de cerrado julgamento crítico. Freud entende que, em função de uma identificação do ego com o objeto abandonado, na melancolia a perda objetal se transforma numa perda do ego. E assim, conclui Freud, se a melancolia toma de empréstimo ao luto alguns de seus traços, ela teria no entanto, diferentemente do luto, um caráter patológico.

Quero tomar à teoria freudiana da melancolia alguns de seus traços, mas para lê-la de uma outra perspectiva, destituída do caráter negativo e patológico por ele apontado. Com efeito, a atitude crítica frente ao eu, o seu ensimesmamento e inibição, acarretando um estado de aparente desinteresse pelo mundo, numa busca de isolamento e contemplação, como podemos perceber nos poetas mineiros em apreço, revelam antes uma atitude de desconfiança e de problematização do mundo moderno, centrado numa racionalidade instrumental e abstrata, que constitui o sujeito pelo viés da renúncia e do sacrifício de uma parte de si. Evidenciam tais atributos tratar-se o melancólico de "um ser pensante em estado de perplexidade". ${ }^{9}$ Nesse sentido, a acedia do melancólico e seu desligar-se do mundo exterior não resulta da preguiça nem do sono. Se ele se paralisa pelo pensamento, é porque registra uma perda de sentido do trabalho,

\footnotetext{
${ }^{8}$ FREUD, 1974. Livro 11 - Metapsicologia, p. 168.

${ }^{9}$ MATOS, 1993. p. 167.
} 
admitindo a dúvida que rompe com a continuidade da história e instaura o descontínuo. Curiosamente, na representação que o pintor renascentista alemão Albrecht Dürer faz da Melancolia, ela é alada e está bem acordada, posta numa atitude contemplativa. Está associada a objetos geométricos, como o compasso e a esfera, e a uma edificação inacabada. Ela sinaliza para a ambivalência da razão cartesiana, abstrata e calculista, e sua teleologia do ponto fixo. Uma razão que não elimina, conforme mostra Olgária Matos, a incoerência da vida. ${ }^{10}$ Desse modo, em sua feição de inacabamento e incompletude, a melancolia revela um caráter positivo e produtivo na construção de uma epistemologia crítica da racionalidade moderna.

Essa compreensão da melancolia encontra-se sobretudo no pensamento de Benjamin. Em Origem do drama barroco alemão, texto de 1928, ele aproxima o século XVII alemão do século XX; torna-os contemporâneos ao apontar entre o mundo barroco e o mundo moderno algumas semelhanças. ${ }^{11}$ Tanto um quanto outro são marcados pela ruína e a decadência, pela completa imanência do tempo histórico convertido em natureza, e da natureza transformada em história. Em ambos, a destinação à morte e à decomposição: no drama barroco, a transitoriedade de tudo que é corpóreo e temporal; no drama moderno, a redução de tudo à condição de mercadoria, configurando um mundo caduco, completamente reificado e sem comunicação. Mundo caduco este, por sinal, tão presente na poesia de Drummond. No entanto, se Benjamin vê semelhanças entre eles, o seu intento é o de procurar, pela via do alegórico e de uma meditação melancólica, salvar o Barroco, salvando a si e a nós mesmos, alojados no interior da modernidade. Desse modo, na reflexão freudiana sobre o luto e a melancolia, Benjamin haverá de estranhar o fato de, no trabalho do luto, o sujeito abrir mão do objeto amado, com o qual se identificava, resignando-se com sua perda. Renúncia que, para ele, seria decorrente de uma coerção. Na melancolia, entretanto, o sujeito reluta em renunciar ao objeto perdido, se opõe a isso por meio de uma atitude contemplativa. Atitude que problematiza o puro ativismo e se detém sobre uma história dolorosa, propiciando a persistência do passado e o retorno do objeto perdido. Daí que o melancólico seja acometido de inspirações e visões, de fantasmasgorias. Mas, é na medida em que não cede à coerção

\footnotetext{
${ }^{10}$ MATOS, 1993. p. 166-168.

${ }^{11}$ BENJAMIN, 1984.
} 
da renúncia, que se torna possível à meditação melancólica a redenção do passado, a crítica de uma história teleológica.

No Drama Barroco, Benjamin afirma um saber melancólico, a exemplo do saber do cortesão. Trata-se de um saber que se opõe ao projeto do príncipe de estabelecer um estado imutável às coisas. Um saber próprio do alegorista, que toma a ruína como fragmento morto do que restou da vida, que o arranca de seu contexto, mata-o, para obrigá-lo a significar. Ao sumariar as diferentes teorias, medievais e renascentistas, de explicação da melancolia, Benjamin não deixa de ressaltar o seu caráter ambivalente, relacionado à genialidade e à loucura. Mas destaca a capacidade do olhar subjetivo do melancólico, capaz de detectar a ambição e os vícios dos tiranos, dotado do dom divinatório e profético. Capacidade esta que não escapou ao próprio Freud, ao assinalar que o sujeito melancólico se consome num trabalho interno, visto que parece dotado de "uma visão mais penetrante da verdade do que outras pessoas que não são melancólicas". ${ }^{12}$

Num dos poemas de "Lanterna mágica", de Alguma poesia, dedicado a Belo Horizonte, Drummond afirma: "Meus olhos têm melancolia/ minha boca tem rugas." Capital modernista, produto de uma razão planificadora e higiênica, capaz no entanto de conciliar os sonhos libertários de uma Minas ancestral e insurrecta com o progresso e a racionalidade ordenadora dos tempos modernos, dessa cidade certa vez disse o poeta Drummond, então professor de Geografia num colégio de Itabira, em carta de 1926 a Abgar Renault: "Eu de cá, você de lá e esse bruto sertão no meio (tudo que não é Belo Horizonte, em Minas, é sertão fechado).” Para o olhar do poeta, a nova capital mineira constitui o território por excelência do espaçotempo da modernidade, em contraponto com o "sertão fechado" que a circunscreve, representante este de uma Minas primitiva, colonial e barroca. Minas esta, no entanto, que habita o coração da cidade moderna, conferindolhe um ar provinciano incompatível com as aspirações universalistas do poeta.

Mas o fato é que os versos acima nos mostram que estamos diante do olhar melancólico, capaz de problematizar o seu tempo, como no poema "Nosso tempo", em A rosa do povo, onde diz: "Este é tempo de partido,/ tempo de homens partidos. (...) Este é tempo de divisas, / tempo de gente cortada./ De mãos viajando sem braços,/ obscenos gestos avulsos." Tratase de um tempo de ruínas, de decomposição, de fragmentos, de morte. De um tempo de perdas, propício à elaboração melancólica. Mas cabe

${ }^{12}$ FREUD, 1974. p. 168. 
indagar: com que objetos perdidos se identificam esses poetas? Exatamente o que os torna melancólicos?

Como resposta a essas questões, vejo dois cenários que se imbricam. Um de ordem mais intrínseca ao espaço literário, ligado à representação do poeta no âmbito da tradição; outro, mais extrínseco, remetendo ao papel do poeta no contexto da modernidade nacional. Consideremos antes o aspecto mais imanente ao poético.

Penso ser possível relacionar a melancolia dos poetas mineiros aqui comentados à perda da aura, na medida em que a modernidade, com seu gesto de negação e ruptura, inviabiliza a permanência de qualquer tradição. Acelerada pelas técnicas de reprodução da obra de arte, a perda da aura comportaria um aspecto positivo, conforme demonstrado por Walter Benjamin, na medida em que torna a arte mais próxima das massas urbanas, possibilitando a sua politização. ${ }^{13}$ Desaloja-a do espaço da tradição, de sua condição parasitária do culto. No entanto, ao negar o diálogo com a tradição, o artista e, em particular, o poeta se vêem destituídos de uma parte de si, que permitiria a compreensão do seu quefazer artístico. Residiria aí aquilo que Freud designava como uma perda do eu. Acrescentaria: de um eu lírico. Por essa via se possa talvez entender o questionamento drummondiano do eu como objeto da poesia, a sua visão crítica do sujeito lírico.

Num ensaio clássico sobre a poesia de Drummond, Antonio Candido detecta uma "inquietude com o eu", culminando na auto-negação pelo sentimento de culpa, e cujas manifestações indiretas despontam nas "alusões à náusea, à sujeira, ou o mergulho em estados angustiosos de sonho, sufocação e, no caso extremo, sepultamento, chegando ao sentimento de inumação em vida". ${ }^{14}$ Ora, não há como não relacionar tal inquietude com aquele empobrecimento e esvaziamento do eu típico do melancólico. O resultado disso, como indica Candido, é o do questionamento de um eu precário e insatisfatório, "impura matéria privada", como objeto da poesia, expondo-se ao olhar de outros. Por sinal, Lambotte ressalta o problema especular do melancólico, assinalando a sua dificuldade ante o olhar de outrem. ${ }^{15}$

\footnotetext{
${ }^{13}$ Cf. BENJAMIN, 1985. v. 1, p. 165-196.

${ }^{14}$ CANDIDO, 1977. p. 100.

${ }^{15}$ Cf. LAMBOTTE, 2000.
} 
Mas o que importa destacar aqui é o fato de que essa inquietude e questionamento do eu em Drummond corrói de certa forma as bases do lirismo, da poesia como expressão da subjetividade, e prepara o terreno para uma poética não das coisas, mas do nome das coisas, conforme mostram seus poemas metapoéticos de A rosa do Povo por exemplo. Em sua autocrítica do eu, Drummond se contrapõe ao modelo hegeliano da lírica, centrado na subjetividade auto-suficiente e auto-consciente do indivíduo burguês, capaz de representar um mundo interior completo. ${ }^{16}$

Em relação à perda da aura, percebe-se em Drummond uma atitude ambivalente, de compreensão e de desconfiança. Cabe ter presente aqui a ambigüidade da noção de aura em Benjamin: enquanto distanciamento, ela contém uma dimensão elitista e produtora de mistificações, mas, ao mesmo tempo, indicia um distanciamento estratégico, garantia de um olhar mais crítico. Pode ser a isso que se refira Baudelaire no poema "O Albatroz", em que compara o poeta ao pássaro; semelhante ao albatroz baudelairiano, é na distância, voando no azul mais alto, que o poeta se mostra mais belo. Dessa dimensão mais positiva parece dar testemunho o poema "Nota social", contido em Alguma poesia.${ }^{17}$ Nele o poeta, de forma enfática, proclama o seu sentimento: "O poeta está melancólico." Talvez que desgostoso quanto aos rumos do poeta num mundo de relações mecânicas, num mundo caduco, a inviabilizar um projeto de autêntica comunicação e comunhão da poesia com o seu tempo, com os seus destinatários, com o povo. Uma vez quebradas as cadeias de uma tradição estéril, uma vez superadas as distâncias auratizantes, nenhuma garantia de um canto geral, coletivo. No palco das ruas e praças, em meio ao rumor das massas, o poeta pode continuar cantando só, num "sol danado". Incomunicável.

O poema explicita uma desconfiança frente ao universo da publicidade. O mundo moderno quer o poeta cada vez mais personagem público, a ser exposto na cena pública, assunto para as colunas sociais. Perseguem-no a política, as máquinas fotográficas, a imprensa, os automóveis. E as ovações e vaias do público. As engrenagens da publicidade podem fazer do poeta um mega-star, podem fazer do seu nome marca de produto, podem fazer da poesia mercadoria. Outros

\footnotetext{
${ }^{16}$ Cf. HEGEL, [s.d.]. p. 215-274.

${ }^{17}$ ANDRADE, C. D., 1983. Volume único, p. 83-84.
} 
grilhões ameaçam aprisionar o poeta, sob a forma sutil e abstrata das leis de mercado. E o poeta, como a cigarra que o metaforiza no poema, pode continuar no seu canto solitário, indestinado, cantando numa "árvore gorda, prisioneira de anúncios coloridos". Ambígua pois a relação do poeta com o público, com as massas. Marcada por um duplo movimento. O de aproximação, anulação da distância, na abertura para o contato, o possível diálogo: "O poeta chega na estação." E o de recuo e enclausuramento: "O poeta fecha-se no quarto."

Como sugere o poema "Nota social", o mundo moderno com sua sedução não garante a salvação do poeta. Antes, indica que nele ele não tem lugar, a não ser como elemento marginal. E assim se desenha um outro dilema: ao poeta - elemento marginal e deslocado - atribui-se a tarefa de redenção da alma nacional. O que me leva àquele segundo cenário, mais extrínseco: o das relações dos intelectuais mineiros da primeira geração modernista com o projeto do Estado Nacional do pós30, em especial com o Estado Novo.

Em carta de 10-11-1924, depois de reprovar a atitude cética dos jovens modernistas mineiros, o fato de serem muito intelectuais de gabinetes, sem exercitarem a arte da conversação com o povo simples, a alegria de viver, Mário de Andrade assim anima o jovem Carlos Drummond de Andrade: "Nós temos que dar ao Brasil o que ele não tem e que por isso até agora não viveu, nós temos que dar uma alma ao Brasil e para isso todo o sacrifício é grandioso, é sublime. E nos dá felicidade”. ${ }^{18}$

Diria então que o olhar melancólico de Drummond tem a sua matriz nesse apelo de Mário de Andrade, com toda a autoridade de uma vida dedicada ao país; nessa tarefa atribuída ao poeta, ao intelectual, de dar uma alma ao Brasil. Em termos do Estado Novo, isso significa construir uma imagem pedagógica e totalizante do Brasil, capaz de garantir a sua modernização. Tarefa cujos impasses e dificuldades, Drummond já parece antever. E o que o confronta com um difícil dilema: nacionalismo ou universalismo. Nesse sentido, em tom discordante, Mário lhe escreve uma carta sem data, procurando desfazer o dilema ao propor-lhe um nacionalismo universalista. ${ }^{19}$

\footnotetext{
${ }^{18}$ ANDRADE, M. 1988. p. 23.

${ }^{19}$ Cf. ANDRADE, M. 1988. p. 130.
} 
Se, de um lado, como intelectuais engajados e membros da "cidade letrada”, daquele anel protetor do poder, conforme nos ensinou Ángel Rama, ${ }^{20}$ nossos dois poetas se encontram no campo do agir pragmático, da ação política, colocando-se a serviço de um projeto de nação em que predomina a ação centralizadora do Estado, mas capaz de garantir o acesso à modernidade, de outro lado, no âmbito da literatura, como artistas da palavra, eles elaboram um saber melancólico, que vai se revelar desconfiado do projeto a que servem. Raciocinando com Peter Bürger, ${ }^{21}$ diria que, enquanto instituição, a literatura vai cumprir um papel relevante em favor do projeto cultural e educacional do Estado Novo, em prol da modernização do país, mas, em contrapartida, ao afirmarem uma estética da melancolia, esses poetas mineiros vão produzir, de forma paradoxal, uma crítica contundente da modernização estadonovista. O que ajuda a explicar os desconfortos, as tensões, contradições e dilemas que eles experimentam.

Daí a ambigüidade de suas posições frente ao mundo moderno, como muito bem ilustra o poema "Endecha do funcionário no Palácio da Educação", de Abgar Renault, um intelectual preocupado em modernizar o sistema educacional do país. Nesse poema, o poeta evidencia seu desconforto com o novo e moderno prédio do Ministério da Educação, no Rio, preferindo o antigo Rex. Repudiando uma racionalidade iluminista a serviço do controle e do cálculo, diz ele: "Nada de prédio de vidro em que ar e luz entrem e se espalhem/ com um método minucioso que sabe cada canto, cada mesa, cada arquivo, cada gaveta." E, ao final do poema, se posiciona:

Não quero o novo, o grande, o claro, o alegre:

prefiro a sala velha sem luz, sem ar, sem água gelada, o prédio velho, sem jardim, sem estátuas nuas, sem peixes, sem nada, nada do que de moderníssimo aqui existe, porque, por menos que pareça, sou esquerdo, antigo e triste..$^{22}$

Tal posicionamento, que evoca de certo modo a autonomia da arte e a estética do gênio, parece evidenciar uma crise das utopias e dos sonhos que abraçaram os intelectuais da Rua da Bahia. Utopias e sonhos que parecem ter se desmoronado no mundo concreto, da ação prática. No seu

\footnotetext{
${ }^{21}$ Ver, a propósito, o ensaio Literary Institution and Modernization. In: BÜRGER, 1992. p. 3-18.

${ }^{22}$ RENAULT, 1990. p. 94-95.
} 
intuito de aliar cultura e política, ao fim e ao cabo revelam-se desencantados com a política, implicando a ruína de tantos sonhos alimentados. É o que demonstra uma carta de Drummond a Abgar, escrita em 20-03-1961, comentando o novo governo (de Jânio Quadros):

Sobre o novo governo, meu caro, o que posso dizer é que mais uma vez verifico que governo nenhum é do meu agrado, mesmo se eu ajudei a constituí-lo. O poder é realmente uma coisa feia e má, e só teoricamente nos permite alimentar ilusões de ordem, justiça e eficiência.

Essa atitude cética em relação ao poder, extensiva aos homens públicos, não deve nos levar a atribuir a Drummond uma atitude de alienação, frente aos acontecimentos, como poderia sugerir a epígrafe de Claro enigma, tomada a Valéry: "Les événements m'ennuient", como muito bem mostrou Vagner Camilo em trabalho recente. ${ }^{23}$ Indica antes a adoção de um distanciamento estratégico em relação à cena política e histórica.

Todavia, uma melhor compreensão da relação dos intelectuais mineiros com o Estado Novo não pode se limitar a uma análise da cena histórico-política. Cabe levar em conta também a cena psíquica. Pode-se dizer que tal relação teria lastros psíquicos na sociedade patriarcal mineira. O Estado Novo encarnaria, então, a figura ambivalente do pai. De um lado, o pai autoritário e castrador (o pai edipiano), com o qual Drummond, por exemplo, teria de romper, negando os laços de sangue. Daí a diáspora para o Rio de Janeiro. De outro, há um pai imaginário que garante o triunfo do simbólico - as "escrituras do pai". O Estado Novo, como deslocamento e condensação dessa figura ambivalente do pai, possibilitaria a esses intelectuais mineiros o usufruto do simbólico, em termos de criação artística e literária, na medida em que lhes garante o sustento diário, relativa estabilidade econômico-financeira.

Na cena psíquica e social, portanto, a melancolia em Drummond tem raízes no processo de separação que o afasta da casa paterna, da origem. De tal processo decorre um movimento pendular, marcado pela oscilação entre a tristeza - sinal da separação e início da aventura simbólica - e a alegria, resultado de sua instalação no universo do artifício, do símbolo. Nesse sentido, os poemas de Drummond e Abgar, como aventura do corpo e dos signos, testemunham sobretudo os afetos - da alegria e da tristeza.

${ }^{23}$ Cf. CAMILO, 1999. 


\section{Referências Bibliográficas}

ANDRADE, Carlos Drummond de. Poesia e prosa. Rio de Janeiro: Nova Aguilar, 1983. Volume único.

ANDRADE, Mário de. A lição do amigo: cartas de Mário de Andrade a Carlos Drummond de Andrade. 2. ed. rev. Rio de Janeiro: Record, 1988.

BENJAMIN, Walter. Origem do drama barroco alemão. São Paulo: Brasiliense, 1984.

BENJAMIN, Walter. A obra de arte na era de sua reprodutibilidade técnica. In: Obras escolbidas: magia e técnica, arte e política. São Paulo: Brasiliense, 1985. v. 1.

BENJAMIN, Walter. Obras escolhidas. São Paulo: Brasiliense, 1989. v. III: Charles Baudelaire - um lírico no auge do capitalismo.

BOMENY, Helena. Guardiães da razão: modernistas mineiros. Rio de Janeiro: Ed. UFRJ; Tempo Brasileiro, 1994.

CAMILO, Vagner. Da rosa do povo à rosa das trevas: classicismo, melancolia e cosmovisão trágica na lírica de Drummond. 1999. Tese (Doutorado em Teoria Literária) - Unicamp, Campinas, SP.

CANDIDO, Antonio. Inquietudes na poesia de Drummond. In: Vários escritos. 2. ed. São Paulo: Duas Cidades, 1977.

FREUD, Sigmund. Luto e melancolia. In: Obras completas. ESB. Rio de Janeiro: Imago, 1974. Livro 11 - Metapsicologia.

HEGEL. A poesia lírica. In: Estética. Lisboa: Guimarães Editores, [s.d.].

KRISTEVA, Julia. Sol negro: depressão e melancolia. Rio de Janeiro: Rocco, 1989.

LAMBOTTE, Marie-Claude. Estética da melancolia. Rio de Janeiro: Companhia de Freud, 2000.

LOPES, Denilson. Nós os mortos: melancolia e Neo-Barroco. Rio de Janeiro: Sette Letras, 1999.

MATOS, Olgária C. F. Ulisses e a razão insuficiente: geometria e melancolia. In: . O iluminismo visionário: Benjamin leitor de Descartes e Kant. São Paulo: Brasiliense, 1993.

RAMA, Ángel. A cidade das letras. São Paulo: Brasiliense, 1985.

RENAULT, Abgar. Obra poética. Rio de Janeiro: Record, 1990.

SOUZA, Eneida Maria de (Org.). Modernidades tardias. Belo Horizonte: Ed. UFMG, 1998. 


\section{Resumo}

Na obra de importantes poetas modernistas mineiros é recorrente a imagem do poeta melancólico ou o tema da melancolia. É o caso, por exemplo, de Carlos Drummond de Andrade e Abgar Renault. Objetivando uma compreensão mais adequada dessa figuração do poeta, o trabalho ora proposto empresta à melancolia um caráter produtivo, a partir de uma perspectiva benjaminiana, enquanto possibilitadora de uma epistemologia crítica da racionalidade moderna. Nesse sentido, tenta articular poesia, nação e modernidade, evidenciando duas hipóteses explicativas do fenômeno: uma de ordem mais intrínseca, ligada à representação do poeta no âmbito da transição literária; outra, de caráter mais extrínseco, relacionada ao papel dos intelectuais mineiros no contexto da modernidade nacional.

\section{Resumen}

En la obra de importantes poetas modernistas mineiros es recurrente la imagen del poeta melancólico o el tema de la melancolía. Es el caso, por ejemplo, de Carlos Drummond de Andrade y Abgar Renault. Objetivando una comprensión más adecuada de esa figura del poeta, el trabajo aquí propuesto presta a la melancolía un carácter productivo, a partir de una perspectiva benjaminiana, en cuanto posibilitadora de una epistemología crítica de la racionalidad moderna. En ese sentido, intenta articular poesía, nación y modernidad, evidenciando dos hipótesis explicativas del fenómeno: una de orden más intrínseca, relacionada a la representación del poeta en el ámbito de la transición literaria, otra, de carácter más extrínseco, relacionada al rol de los intelectuales mineiros en el contexto de la modernidad nacional. 